\title{
A IMPORTÂNCIA DA RESIDÊNCIA PEDAGÓGICA DA UFT/ARRAIAS NAS ESCOLAS DO CAMPO E A IMPLEMENTAÇÃO DA OFICINA DE FLAUTA-DOCE
}

The importance of UFT/Arraias Pedagogical Residence in field schools and the plate-flute workshop implementation

La importancia de la Residencia Pedagogica UFT/Arraias en las escuelas del campo

y la implementación de un taller de flauta dulce

Aparecida de Jesus Soares Pereira*1, Waldir Pereira da Silva², Maristela Firmino da Cunha Gomes $^{3}$, Karolyne Sodré de Moura ${ }^{4}$

1,2,3,4 Laboratório de Educação Musical, Curso de Licenciatura em Educação do Campo, Universidade Federal do Tocantins-UFT, Arraias -TO, Brasil.

*Correspondência: Curso de Licenciatura em Educação do Campo, Universidade Federal do Tocantins - UFT, Campus Professor Dr. Sérgio Jacintho Leonor, Av. Juraíldes de Sena e Abreu, Setor Buritizinho/ sala 10 - Bloco Bala, Arraias - Tocantins, Brasil.CEP:77.330-000.e-mails: cida.soares@uft.edu.br/waldir.pereira@uft.edu.br/ gmaristela6@bol.com.br/karolaynemoura@uft.edu.br

\section{Artigo recebido em 03/04/2020 aprovado em 09/04/2020 publicado em 17/04/2020.}

\section{INTRODUÇÃO}

Este trabalho tem por objetivo apresentar o relato de experiência como residente do Programa Residência Pedagógica, vinculado ao Curso de Licenciatura em Educação do Campo Códigos e Linguagens Artes Visuais e Música da Universidade Federal do Tocantins - Campus de Arraias, tendo como campo de atuação, a Escola Estadual Girassol de Tempo Integral Agrícola David Aires França. No decorrer das atividades, muitas foram as experiências, sendo elas positivas e negativas. Houveram momentos na escola que de certa forma motivavam a continuar o processo, e outros em que o desejo era desistir.

Ao adentrar a escola, percebeu-se a carência que os alunos tinham em relação à afetividade. Assim, o Projeto Residência Pedagógica - PRP, que tem a intenção de colaborar na formação docente, também se apresentou como um reforço colaborativo da educação favorecendo o desenvolvimento do conhecimento social, político e cultural de todos os envolvidos, inclusive dos alunos e da escola que se mostraram muito receptivos ao projeto e às propostas do mesmo.
Toda escola tem os seus problemas que necessitam serem resolvidos, e com a Escola Agrícola não é diferente. O mais perceptível foi que os alunos tinham uma enorme carência afetiva. Para Freire (1983), "a educação é um ato de amor, por isso um ato de coragem" (FREIRE, 1983, p. 104). A princípio, imaginava-se que seria apenas cumprido o papel do residente com o objetivo de atender as especificidades do PRP, mas foi notório o apego e carinho que os alunos tiveram naquele momento com o programa e com os residentes, indo além das expectativas e objetivos imaginados. Ali o residente teve que cumprir para além do seu papel de educador, sendo também mãe, amigo, conselheiro, psicólogo e atendendo as várias necessidades que iam se apresentando no decorrer do processo educacional.

Segundo Polonia e Dessen,

Faz-se mister, sobretudo, estimular as produções acadêmicas direcionadas ao estudo do envolvimento da família com a escola, transformando-as em fomento e em mecanismos que contribuam para o planejamento de políticas e de programas educacionais (POLONIA; DESSEN, 2005, p. 310). 
Não basta tornar-se pai ou mãe, mas conscientizar a todos da igualdade de responsabilidades (Escola/família/sociedade). É normal muitas vezes o professor se sentir incapaz de resolver as diversas situações que venham a ocorrer, e isto aconteceu nas atividades do PRP por não poder ajudar a alunos que estavam com dificuldades familiares. Assim, diante desta dificuldade surgiu o interesse em procurar um método de aproximar mais dos alunos e criar certo vínculo com eles, um meio de criar confiança. Então, pôde-se perceber a carência pelo ensino da música na escola, já que o único projeto que tinha ali era a Fanfarra que estava a algum tempo parada. Então surgiu a ideia em iniciar o projeto de Flauta-Doce pelo PRP, com o intuito de ensinar os alunos a tocarem o instrumento. Para isso, foi feito o convite de participação aos alunos pelo residente, que divulgou o projeto nas salas de aula. Na aula inicial havia apenas um único instrumento sendo uma flauta do professor - residente. Dessa forma, Burke (2003) diz que "o professor não é quem ensina, mas quem ajuda o aluno a aprender e aprende com ele. $\mathrm{O}$ professor não mostra; ajuda o aluno a enxergar e descobre com ele" (BURKE, 2003, p. 59). O objetivo principal era ensinar os alunos a tocarem o instrumento, não saindo de lá grandes tocadores até porque os encontros eram poucos. A intenção era apresentar a eles e despertar um conhecimento maior, e de fato isso aconteceu. Por várias vezes foi constatado ao chegar à escola que em diversos pontos, os alunos estavam tocando e estudando o instrumento, sempre em constante aprendizado.

Outro mérito conquistado entre eles foi a coletividade e a união que se fortaleceu, percebia-se a força de vontade de um ajudando o outro, o impulso e a boa vontade. Percebe-se com isso, que realmente o gosto em aprender de um profissional da educação deve ser uma busca diária e constante. O profissional também deve ter a consciência das diversas situações que podem surgir em sua práxis.

\section{METODOLOGIAS E MATERIAIS}

A escola não tinha condições para comprar os instrumentos para os alunos, e nem o PRP e o residente tinham recursos financeiros próprios para a aquisição dos mesmos. Sendo assim, o residente aprofundava mais nas aulas teóricas e as práticas não davam para serem executadas, pois faltavam instrumentos. Com o passar dos dias, uma professora da disciplina de Educação Física da escola se interessou pelo projeto e se prontificou a ajudar, doando as flautas para os alunos. Todos ficaram muito gratos e felizes, pois era o que estava faltando para concretizar o projeto de fato. Já com as flautas em mãos foram colocadas em prática toda a parte teórica aprendida em sala de aula. Todos estavam muito empolgados e quando foi iniciada a primeira turma haviam apenas 7 alunos, e no decorrer das aulas o número aumentou para 12 alunos, onde todos se dedicavam e mantinham o esforço para aprender mais e mais sobre o instrumento. Os alunos demonstravam facilidade para tocar, pois uma música em que se costuma ensinar e aprender a tocar em 2 semanas, em uma semana já estavam todos afiados. Para os alunos era algo novo e empolgante. Podia-se perceber também quando ao encontrarem a residente na escola eles costumavam sempre perguntar quando seria a próxima aula mesmo sabendo que as aulas só aconteciam duas vezes na semana.

Quanto à metodologia utilizada optou-se pela Filosofia Suzuki que parte do princípio de que todos podem aprender. Segundo ele "o objetivo da educação do talento é treinar as crianças, não a ser músicos profissionais, mas a ser bons músicos e mostrar toda a sua habilidade em qualquer profissão que escolherem" (SUZUKI, 1994, p. 76). Assim, o talento não é um acaso do nascimento, a exemplo disto, todos podem aprender uma habilidade, neste caso, a tocar a flauta 
doce, cada um ao seu tempo, mas de forma a dominar o vocabulário comum do universo da flauta doce, alguns podem ter mais dificuldades para o aprendizado outros um desenvolvimento bem maior.

Outro método utilizado foi o de Álvares (2005) na qual destaca a observação da propriocepção, os movimentos realizados pelos dedos e mãos para tocar o instrumento, que reafirma um dos estudos do neurologista britânico, Oliver Sacks (2007) que tem trazido grande contribuição para os estudos do ensino musical ao afirmar que a atividade musical envolve várias funções do cérebro (emocional, motora, cognitiva) muito mais do que as que usamos para o outro grande feito humano, a linguagem. Com isso é notório a forma tão eficaz de aprendizado já que o instrumento flauta doce (sopro) aparentemente não demonstra tanta dificuldade para manusear. De fato, vários métodos foram pesquisados e estudados no sentido de melhor atender e desenvolver o ensino e a aprendizagem dos alunos.

\section{RESULTADOS E DISCUSSÃO}

A participação no Projeto Residência Pedagógica proporcionou muitas experiências e uma grande oportunidade para que o ensino de música pudesse ser levado à escolas que tinham dificuldade a este acesso. Sendo assim, a contribuição deste projeto nas escolas, foi de suma importância criando um elo entre escola, universidade e comunidade tanto do urbano como rural, uma união necessária pois vê-se como uma forma dos alunos quebrarem aquela pressão ou até mesmo o medo que tinham acerca de uma universidade, adquirindo assim maior segurança para integrar uma universidade, visto que pelo fato de ser uma escola do campo já tem um papel dentro das universidades, e cursos ligados a eles.

\section{CONCLUSÃO}

Nota-se que o Programa Residência Pedagógica é de suma importância para o processo de formação docente, como também para a formação continuada de professores e a educação de modo geral. Muitos são os desafios a serem enfrentados, mas, as contribuições e os retornos motivam pela busca da continuidade e a permanência do Programa.

\section{AGRADECIMENTOS}

À Capes pela bolsa de estudos. À instituição UFT por tornar possível a realização do programa de Residência Pedagógica. À Preceptora Maristela pelo apoio e compreensão, sempre presente e fazendo até mesmo o impossível para ajudar a todos. À Escola Estadual de Tempo Integral Girassol David Aires França pelo acolhimento. Enfim, muita gratidão a Deus por essa experiência.

Todos os autores declararam não haver qualquer potencial conflito de interesses referente a este artigo. 


\section{REFERÊNCIAS}

ÁLVARES, S. L. A. Teorias do desenvolvimento cognitivo e considerações sobre o aprendizado da música. In: Simpósio Internacional de Cognição e Artes Musicais, 1., 2005, Curitiba. Anais... Curitiba: UFPR, 2005. p. 63-71.

BURKE, $\quad$ T. $\quad$ J. O professor revolucionário. Petrópolis: Vozes, 2003.

DRUMMOND, E. Iniciação à flauta doce. Ceará: Softcraft Publicações Ltda. 1988.

FREIRE, Paulo. Educação como prática da Liberdade. 14. ed. Rio de Janeiro: Paz e Terra, 1983.

POLONIA, A. C.; DESSEN, M. A. Em busca de uma compreensão das relações família e escola. Psicologia escolar e educacional. v.9. n. 2, p. 303-312. 2005.

SACKS, O. Alucinações musicais: relatos sobre a música e o cérebro. São Paulo: Companhia das Letras. 2007.

SUZUKI, S. Educação é Amor. 2. ed. Santa Maria: Palotti, 1994.

TARDIF, Maurice. Saberes docentes e formação profissional. 3. ed. Petrópolis, RJ: Vozes, 2002. 